\title{
Subclinical neurological involvement in Behçet's disease
}

\author{
Tugba Tunç, Hülya Ortapamuk*, Seniha Naldöken*, Ufuk Ergun, Deniz Ciliz**,

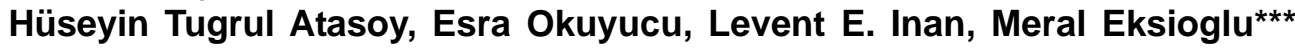

Department of Neurology, Ankara Research and Training Hospital, Ministry of Health, Ankara, *Departments of Nuclear Medicine and ${ }^{* *}$ Radiology, Ankara Numune Research Hospital, Ministry of Health, Ankara, ${ }^{* \star \star D e p a r t m e n t ~ o f ~ D e r m a t o l o g y, ~ A n k a r a ~ R e s e a r c h ~ a n d ~}$ Training Hospital, Ministry of Health, Ankara, Turkey

Context: Behçet's disease (BD) is a multisystem inflammatory disorder with unknown etiology characterized by recurrent oral and genital aphthous ulcers and uveitis. Behçet's disease can affect the central nervous system. Aims: We aimed to investigate subclinical neurological involvement in patients who were suffering from BD and who had no neurological symptoms. Settings and Design: A total of 49 patients were included in the study. For the investigation of subclinical neurological involvement, the patients received imaging and/or neurophysiologic evaluations. Materials and Methods: The evaluation techniques were as follows: single photon emission computed tomography, 33 patients; cranial magnetic resonance imaging (MRI), 25 patients; brainstem auditory evoked potential examination, 36 patients; and electroencephalography (EEG), 30 patients. Statistical Analysis Used: The Mann-Whitney $U$ test and Wilcoxon Rank-Sum W test were used. Results: Patients in the MRI and EEG groups showed significantly more abnormalities than did age- and gender-matched controls. Conclusions: Early diagnosis of neurological involvement in BD is important in reducing or preventing complications. Cranial MRI and EEG were found to be useful for detecting subclinical neurological abnormalities in patients with Behçet's disease.

Key words: Behçet's disease, brainstem auditory evoked response, electroencephalography, magnetic resonance imaging, single photon emission cranial tomography

Behçet's disease (BD) is a multisystem inflammatory disorder with unknown etiology characterized by recurrent oral and genital aphthous ulcers and uveitis. Vasculitis is the major pathological feature. ${ }^{[1]}$ It was first described in 1937 by Hulusi Behçet, a Turkish dermatologist. ${ }^{[2]}$ The disease can affect the skin, joints, intestines, lungs, heart and central nervous system. Neurological involvement in BD was first reported by Knapp in $1941^{[1]}$ and it is one of the most serious manifestations of the disease. The reported frequency of nervous system involvement has varied from 5.3 to $38 \% .^{[3]}$ Neurological involvement in BD has been classified into two major forms. ${ }^{[4]}$ One form can be attributed to inflammatory disease in the small veins of the parenchyma in the central nervous system (CNS), with focal or multifocal involvement and this is known as intra-axial neuro-Behçet syndrome (NBS). The other form is caused by thrombosis of the cerebral venous sinus and is known as extra-axial NBS.

In this study we aimed to investigate neurological involvement in patients with $\mathrm{BD}$ who had no neurological symptoms. For this aim, we used neuroimaging and neurophysiologic methods (magnetic resonance imaging [MRI], single photon emission computed tomography [SPECT], brainstem auditory evoked potential testing $[\mathrm{BAEP}]$ and electroencephalography [EEG]).

\section{Materials and Methods}

A total of 49 patients with BD (30 women, 19 men) with a mean age of $34.6 \pm 9.6$ years (range 19-58) were enrolled in this prospective study between January 2000 and January 2003. Our institution's ethics committee approved the study and informed consent was obtained from all participants. The diagnosis of $\mathrm{BD}$ was made according to the international criteria for diagnosis of Behçet's disease. ${ }^{[5]}$ Patients were excluded from the study if they currently had any neurological symptoms or signs or if they had any history of central nervous system disorders such as cerebral infarction, hemorrhage, tumors, etc. Three patients were excluded because of positive findings in their neurological examinations.

Table 1 summarizes the organ system manifestations of BD seen in our patients. The disease was found to be active in every patient at the time of the evaluation. Therapy consisted of steroids, colchicine and vitamin B preparations. Up to the time of the study, mean disease duration was $8.05 \pm 1.32$ years. Methods used for the evaluation of subclinical neurological involvement were EEG, BAEP, MRI and SPECT. Findings from these were 
Table 1: Patients' clinical status

\begin{tabular}{lc}
\hline Clinical findings & Male/Female \\
Oral ulcers & $19 / 30$ \\
Genital ulcers & $16 / 29$ \\
Skin lesions & $7 / 16$ \\
Pathergy & $8 / 10$ \\
Eye lesions & $12 / 17$ \\
Arthropathy & $3 / 10$ \\
\hline
\end{tabular}

compared with those of controls.

\section{SPECT}

A total of 33 patients (19 women, 14 men) underwent SPECT. Their mean age was $35.9 \pm 10.04$ years (range 19 to 58 years). The control group consisted of 23 women whose data were obtained in a study of menstrual migraine. The mean age of this group was $34.2 \pm 5.2$ years. Single photon emission computed tomography was performed using an Elscint SPX 6 gamma camera (Ashby GD, UK). A parallel isolated collimator for general use with low energy was selected. Data were collected in a $64 \times 64$ matrix and between $1.5200 \mathrm{~m}$ and 360-degree angles (25 seconds/degree, 6 degree intervals). The SPECT images (coronal, sagittal and axial) were processed with backprojection and by MET2 filters. The pharmaceutical agent was 99-mTc-HMPAO. This was prepared by the addition $2.2 \mathrm{GBq}(60 \mathrm{mCi})$ of $\mathrm{Tc}-99 \mathrm{~m}$ to the commercial kit (Brain SPECT, Hungary) with $0.9 \%$ saline solution to make a total of $5 \mathrm{ml}$ for injection. The bottle containing the preparation was shaken mechanically for $10 \mathrm{~min}$ and the preparation was used within one hour. It was injected via an intravenous port as $15 \mathrm{mCi}$ per patient and the imaging was started at five minutes after the injection. Two nuclear medicine specialists who had no information about the patients or controls evaluated the results. Images were evaluated qualitatively in terms of heterogeneous blood flow, focal hypoperfusions or visible asymmetries in gray matter. For quantitative analysis, Geretec two-dimensional software (Europe Nv, Belgium) was used to evaluate the images digitally. Numerical values were obtained for anterior frontal, posterior frontal, temporal, medial occipital and lateral occipital areas. For comparisons in terms of left and right sides, the value of each cerebral side was divided by that of the dominant cerebellar area.

\section{MRI}

A total of 25 patients ( 13 women, 12 men) underwent MRI. Scans were performed with a 0.5 Tesla (T) Vectra scanner (General Electric Medical systems, Milwaukee, USA). The images were taken at the standard position immediately after gadolinium (Gd-DTPA) injection. The patients' mean age in this group was $35.8 \pm 10.39$ years (19 to 58 years). The control group consisted of 20 age- and gender- matched patients ( 11 female, 9 male) with lumbar pain who underwent additional cranial MRI for the purpose of this study. The mean age of the control group was $30.8 \pm 8.7$ years. The results were evaluated by a radiologist who had no information about the patients or controls.

\section{$B A E P$}

Brainstem auditory evoked potential examination was performed on 36 patients ( 13 women, 23 men). The mean age of the patients was $36.39 \pm 9.79$ years (range 19 to 58 years). None of these patients had a history of hearing loss. BAEP was performed with a Medelec synergy EMG instrument (Oxford Instruments Medical, Inc, UK). One electrode was positioned at $\mathrm{Cz}$ and referred to the right (M2) and left (M1) mandibles. Click stimulus and noise were applied to the headphones at $90 \mathrm{~dB}$ and $40 \mathrm{~dB}$, respectively. The click stimulus was applied at a frequency of 10 per second. Measurements were made in both ears as follows. In each ear, a series of 2000 stimuli was presented twice, for a total of 4000 stimuli per ear. For each ear, the average of these two trials was taken. Latencies of Waves I, III, V and I-III and III-V interwave latencies were calculated. Two neurologists evaluated the results blindly. Our laboratory normal values were accepted as a reference in place of a control group. According to these values, the Wave I, III and V latencies were accepted as $1.7 \pm 0.15,3.9$ \pm 0.19 and $5.93 \pm 0.25$ respectively.

\section{EEG}

Thirty patients (18 women, 12 men) underwent EEG evaluation. Their mean age was $35.6 \pm 10.9$ years (range 19 to 58 years). The control group consisted of 18 healthy people (12 women, 6 men) and their mean age was $37.8 \pm 8.5$ years. Electroencephalography was performed with a 21-channel digital EEG machine (Nihon Kohden, Japan). Awake EEGs were obtained with electrodes placed according to the international 1020 placement system. Focal spikes, temporal spikes, polyspikes, occipital spikes, frontal spikes, multifocal spikes, generalized spikewave, polyspike-wave complexes, secondary bilateral synchrony, slow spike waves, $6 \mathrm{~Hz}$ spike waves, bursts of polyspikes, photoparoxysmal response, photomyogenic response, theta and delta waves were accepted as abnormal activity.

\section{Statistical analyses}

SPSS software was used (SPSS, Chicago). The Mann-Whitney $\mathrm{U}$ test and Wilcoxon Rank-Sum W test were used. A $P$ value of less than 0.05 was accepted as significant.

\section{Results}

A total of 49 patients with BD (30 women, 19 men) were enrolled in this prospective study. Of these 49 patients, 33 (19 women, 14 men) underwent SPECT, 25 (13 women, 12 men) underwent MRI, 36 (13 women, 23 men) underwent BAEP and 30 (18 women, 12 men) underwent EEG. Some patients thus underwent more than one type of study.

In the SPECT group, we detected abnormalities in 15 patients $(45.4 \%)$ with visual evaluation of the images [Table 2]. We also evaluated the images quantitatively by dividing a given hemisphere's activation value by that of the dominant cerebellar 
Table 2: Visual evaluation of single photon emission computed tomography images

\begin{tabular}{|c|c|c|c|}
\hline $\begin{array}{l}\text { Patient } \\
\text { no. }\end{array}$ & Sex & Age & $\begin{array}{l}\text { Single photon emission computed } \\
\text { tomography }\end{array}$ \\
\hline 1 & $\mathrm{~F}$ & 27 & Hypoperfusion in left parietotemporal region \\
\hline 2 & $\mathrm{~F}$ & 31 & $\begin{array}{l}\text { Hypoperfusion in right basal ganglia and left } \\
\text { occipital region }\end{array}$ \\
\hline 3 & $\mathrm{~F}$ & 58 & Normal \\
\hline 4 & M & 24 & Hypoperfusion in left frontoparietal region \\
\hline 5 & $\mathrm{~F}$ & 52 & Normal \\
\hline 6 & M & 22 & Normal \\
\hline 7 & M & 46 & Normal \\
\hline 8 & $\mathrm{~F}$ & 47 & Normal \\
\hline 9 & $\mathrm{~F}$ & 21 & Hypoperfusion in left temporal region \\
\hline 10 & M & 39 & Hypoperfusion in left temporoparietal region \\
\hline 11 & M & 30 & $\begin{array}{l}\text { Hypoperfusion in right parietotemporal } \\
\text { region }\end{array}$ \\
\hline 12 & M & 38 & Normal \\
\hline 13 & M & 31 & Hypoperfusion in left parietal region \\
\hline 15 & $\mathrm{~F}$ & 43 & Normal \\
\hline 16 & M & 45 & Hypoperfusion in bilateral basal ganglia \\
\hline 17 & M & 37 & Normal \\
\hline 18 & $\mathrm{~F}$ & 27 & $\begin{array}{l}\text { Hypoperfusion in right parietal and left } \\
\text { temporal regions }\end{array}$ \\
\hline 20 & $\mathrm{~F}$ & 39 & Hypoperfusion in right occipital region \\
\hline 21 & M & 35 & Normal \\
\hline 22 & $\mathrm{~F}$ & 35 & $\begin{array}{l}\text { Hypoperfusion in left temporooccipital } \\
\text { region }\end{array}$ \\
\hline 23 & $\mathrm{~F}$ & 29 & Normal \\
\hline 24 & $\mathrm{~F}$ & 37 & $\begin{array}{l}\text { Normal hypoperfusion in right } \\
\text { parietooccipital region }\end{array}$ \\
\hline 25 & $\mathrm{~F}$ & 19 & Hypoperfusion in left temporal region \\
\hline 26 & M & 35 & Normal \\
\hline 29 & $\mathrm{~F}$ & 29 & Hypoperfusion in right parietal region \\
\hline 32 & M & 35 & Normal \\
\hline 34 & $\mathrm{~F}$ & 23 & Normal \\
\hline 39 & $\mathrm{~F}$ & 36 & Hypoperfusion in right basal gangl \\
\hline 44 & $\mathrm{~F}$ & 37 & Normal \\
\hline 45 & M & 30 & Normal \\
\hline 46 & $\mathrm{~F}$ & 35 & Normal \\
\hline 47 & $\mathrm{~F}$ & 34 & Normal \\
\hline 49 & M & 54 & Normal \\
\hline
\end{tabular}

area. No significant differences were found between BD patients and controls on visual evaluation $(P=0.71)$ or quantitative evaluation $(P=0.33)$ of the SPECT images.

In the MRI group, abnormalities were detected in nine patients (36\%, Table 3). The patients with BD had significantly more abnormalities on MRI than did the control group $(P=0.03)$. In the control group, one patient had areas of gliosis around the lateral ventricles.

In the patients who underwent BAEP evaluation, no significant differences were found between their findings and the normal reference values of our laboratory.

EEGs were abnormal in 11/30 (36.6\%) patients with BD [Table 4]. Patients in this group had significantly more abnormalities on EEG than did healthy controls $(P=0.01)$. No abnormalities on EEG were seen in the control group.

\section{Discussion}

All patients met the diagnostic criteria outlined by the international study group for Behçet's disease, with a positive
Table 3: Results of magnetic resonance imaging evaluation

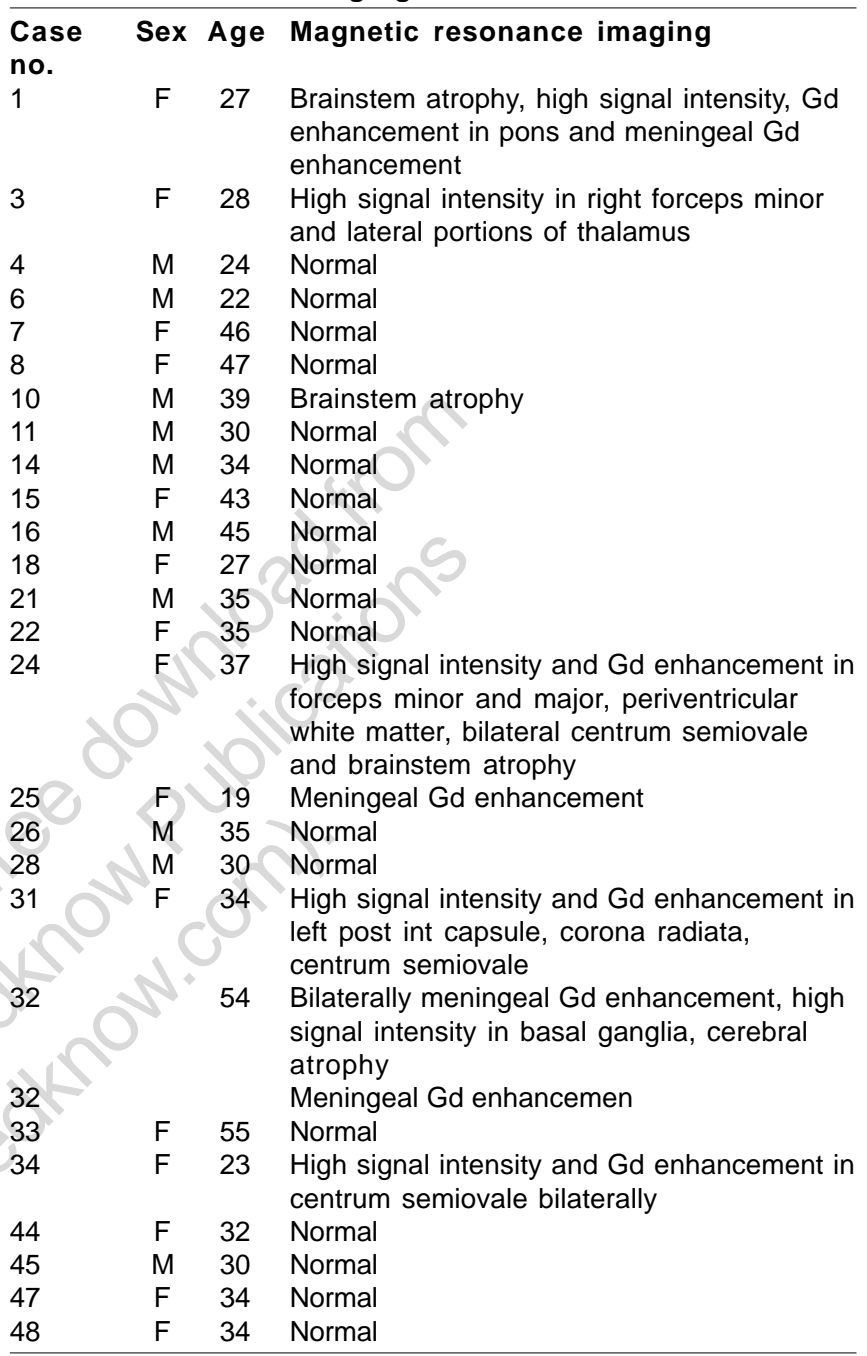

diagnosis being based on the presence of recurrent oral ulceration and two or more of the following: recurrent genital ulceration, cutaneous lesions, ocular lesions or a positive pathergy test. ${ }^{[5]}$ Analysis of our data revealed significant abnormalities on MRI and EEG in patients with BD.

Although we found no significant differences between BD patients and controls on SPECT, perfusional brain disorders in patients with BD have been studied previously with SPECT. ${ }^{[6,7]}$ Brain SPECT has also been found to provide useful clinical information about cerebral cortical abnormalities in patients with neurobehçet's disease. ${ }^{[8]}$ In neurobehçet's disease brain lesions are located more commonly in the brainstem, basal ganglia and hemispheric white matter ${ }^{[9]}$ In our study we found hypoperfusion in the basal ganglia in three patients and in the parietal, frontal, temporal or occipital regions in 13 patients. The rationale for using SPECT in this study was the possibility that detectable changes in brain perfusion might reflect brain abnormalities in BD patients who have no clinical neurological symptoms.

MRI abnormalities were significantly more frequent in our patients with BD compared to the control group. In neurobehçet's 
Table 4: Patients' electroencephalography findings

\section{Case Sex Age Electroencephalography}

no.

$1 \quad \mathrm{~F} \quad 27 \quad$ Normal

$3 \quad$ F $58 \quad$ Epileptiform activity

$4 \quad M \quad 24 \quad$ Normal

$5 \quad$ F 52 Normal

$6 \quad$ M 22 Epileptiform activity paroxysmal activity

$7 \quad M \quad 46 \quad$ Normal

9 F 21 Slow waves in temporal region

$10 \quad M \quad 39 \quad$ Normal

$11 \quad M \quad 30 \quad$ Normal

$13 \quad M \quad 31 \quad$ Normal

$14 \quad M \quad 34 \quad$ Normal

$15 \quad F \quad 43 \quad$ Normal

$16 \quad$ M $45 \quad$ Epileptiform activity

$19 \quad M \quad 32$ Normal

$24 \quad F \quad 37 \quad$ Normal

25

26

27

27

29

30

31

32

33

35

40
43

44

45

48
Epileptiform activity

Normal

Epileptiform activity

Epileptiform activity

Normal

Slow waves in parietooccipital region

Slow waves in temporal region

Normal

Epileptiform activity

Normal

Epileptiform activity

Normal

Normal

Normal

Normal and brainstem atrophy, has not been used much for evaluating patients with BD. In a study of 44 patients with $\mathrm{BD}$ who were neurologically intact, abnormalities were detected in four patients. ${ }^{[13]}$ The BAEP findings in our study were abnormal in 24 of 36 patients $(66.6 \%)$.

Regarding EEG changes in patients with BD, Matsumato reported 10 patients with neurobehçet's disease who had correlated EEG changes. ${ }^{[14]}$ Midorikawa performed the largest EEG study in Behçet's patients and detected abnormalities in $80 \%$ of patients with neurological involvement and in $36 \%$ of patients without neurological signs. ${ }^{[15]}$ In our series we detected EEG abnormalities in $36.6 \%$ of our patients.

In conclusion, our findings suggest that subclinical neurological involvement occurs in patients with BD. Patients with normal neurological examinations might nonetheless have lesions which are too small for detection or which are situated in silent areas of the CNS. However, early diagnosis of neurological involvement in $\mathrm{BD}$ is important in reducing or preventing complications. The possibility of subclinical neurological disease should therefore be considered at the time when BD is first diagnosed.

\section{References}

Serdaroðlu P. Behcet's disease and the nervous system. J Neurol 1998;245:197-205. Behçet H. über rezidivierende Aphthose, durch ein Virus verursachte Geschwüre am Mund, am Auge und an den Genitalien. Derm Wochenschr 1937;36:1152-7. Oktem-Tanor O, Baykan-Kurt B, Gurvit IH, Akman-Demir G, Serdaroglu P. Neuropsychological follow-up of 12 patients with neuro-Behçet disease. J Neurol $1999 ; 246: 113-9$

Siva A, Altintas A, Saip S. Behcet's syndrome and the nervous system. Curr Opin Neurol 2004;17:347-57.

Criteria for diagnosis of Behcet's disease. International Study Group for Behcet's Disease. Lancet 1990;335:1078-80.

6. Avei O, Kutluay E, Argon M, Erdem S, Tahsin Gunes A. Subclinical cerebral involvement in Behçet's disease: A SPECT study. Eur J Neurol 1998;5:49-53.

7. Garcia Hernandez F.J, Ocana Medina C, Mateos Romero L, Sanchez Roman J, Garcia Solis D, Franco-Baux JR, et al. Usefulness of brain SPECT with HMPAO$99 \mathrm{~m}$ Tc and psychological tests for diagnosis of neurological involvement in Behcet's disease. Med Clin (Barc) 2002;119:447-50.

8. Watanabe N, Seto H, Sato S, Simizu M, Wu YW, Kageyama M, et al. Brain SPECT with neuro-Behçet disease. Clin Nucl Med 1995;20:61-4.

9. Vignola S, Nobili F, Piceo P, Gattorno M, Buoneompagni A, Vitali P, et al. Brain perfusion SPECT in Juvenile Neuro-Behçet's Disease. J Nucl Med 2001;42:1151-7.

10. Lee SH, Yoon PH, Park S.J, Kim DI. MRI findings in Neuro-Behçet's Disease. Clin Radiol 2001;56:485-94.

11. Morrissey SP, Miller DH, Hermaszewski R, Rudge P, MacManus DG, Kendall B, et al. Magnetic Resonance Imaging of the central nervous system in Behçet's Disease. Eur Neurol 1993;33:287-93

12. Mirsattari MS, McGinn G.J, Halliday WC. Neuro-Behcet disease with predominant involvement of the brainstem. Neurology 2004;63:382-4

13. Stigsby B, Bohlega S, al-Kawi MZ, al-Dalaan A, el-Ramahi K. Evoked potential findings in Behcet's disease. Brain-stem auditory, visual, and somatosensory evoked potentials in 44 patients. Electroencephal Clin Neurophysiol 1994;92:273-81.

14. Matsumato K. Correlation between EEG and clinicopathological change in NeuroBehçet's Syndrome. Folia Psychiatr Neurol Jpn 1984;38:76-81.

15. Midorikawa T. Electroencephalographic studies on Behçet's Disease with special reference to the electroencephalographies of neurobehçet's disease. Rinsho Shinkeigaku 1975;15:860-9. we were able to find significant abnormalities in BD patients by using this weak magnet, more abnormalities might have been detected with a stronger system.

Brainstem auditory evoked potential testing, although useful in assessing the functional integrity of the lateral acoustic pathway and in detecting severe inflammatory changes, demyelinization
Accepted on 24-06-2006

Source of Support: Nil, Conflict of Interest: None declared. 